\title{
Aqueous extract of Costus Specious ameliorates the toxic effect of lead acetate on transcriptional factors of erythropioesis
}

\author{
Yousef M. Shehata ${ }^{1}$, Mohamed F. Dowidar ${ }^{1}$, Haytham A. Ali ${ }^{2}$, Aaser M. Abdelazim², Eman M. Elmogy ${ }^{3}$. \\ ${ }_{1}^{1}$ Professors of Biochemistry, Biochemistry Department, Faculty of Veterinary medicine, Zagazig University, 44511, Zagazig, Egypt \\ ${ }^{2}$ Lecturers of Biochemistry, Biochemistry Department, Faculty of Veterinary medicine, Zagazig University, 44511, Zagazig, Egypt \\ ${ }^{3}$ Master of Biochemistry, Biochemistry Department, Faculty of Veterinary medicine, Zagazig University, 44511, Zagazig, Egypt
}

\begin{tabular}{l} 
A R T I C L E I N F O \\
\hline Keywords: \\
Erythropioesis, Erythropoietin, FOG- \\
1, GATA-1, SCF
\end{tabular}

A B S T R A C T
Background: The increase use of medicinal plants during last 5
years encourages us to study the possible effects of Coustus
Speciosus.
Objective: In the present study, we tested the effect of Costus
speciosus on the toxicity of Lead acetate.
Results: The results showed an increase of EPO and high
expression levels of GATA-1 and FOG-1 while there is a low
expressional level of SCF in animals treated with Costus
speciosus.
Conclusion: Costus Specious has the ability to ameliorate the
toxicity of lead acetate on erythropioesis.

(C) 2014 Publisher All rights reserved.

\section{INTRODUCTION}

In last 5 years, research on more than 13.000 plants has been conducted. A lot of evidence has collected to demonstrate huge potential of the medicinal plants employed in traditional system ${ }^{(\mathbf{1})}$. World Health Organization (WHO) define medicinal plants as a herbal preparation which is produced by introducing plant materials into various of process which include extraction, fractionation, purification, concentration, or other physical or biological processes which may be produced for basis for herbal product or for the immediate consumption (2). Overall, $80 \%$ of the world's population has dependability in traditional medicine, chiefly based on plant drugs for their primary healthcare ${ }^{(3)}$. Vast numbers of articles focused on the therapeutic activities of medicinal plants; their anticancer, antiviral, anti-diabetics antifungal activities are published ${ }^{(4)}$. In the present work, we study Costus speciosus (Koen) Sm. (Zingiberaceae) (C. speciosus) as a wide used medicinal plant. The plant is widely distributed in India in the tropical or sub-tropical climate from the sea level to the Himalayas, excluding the arid and semi-arid areas of Punjab, Haryana, Rajasthan, Gujarat and the peninsular India ${ }^{(5)}$. The plant rhizomes are used as purgative, anthelmintic, depurative, febrifuge, expectorant, tonic, and useful in burning sensation, constipation, leprosy, worm infection skin disease, fever, asthma, bronchitis, inflammations and anemia ${ }^{(6)}$. The plant is also used as anti-diabetic agent ${ }^{(7)}$. Eremanthin isolated from C. speciosus possess hypoglycemic and antihyperlipidimic activities (8). Its 
antioxidant (9, 10), antifungal (11), antituberculosis (12) hepatoprotective (13) and oestrogenic activities ${ }^{(\mathbf{1 4})}$ are reported. In addition, the ethanol extract of the leaves and rhizome of Costus speciosus possesses anti-inflammatory and antipyretic properties (15). Testing the effect of the plant on the blood cells formation process is lacking many points. This gives us the impetus to test the effect of the plant on the lead acetate-induced deterioration in erythropoiosis. There is an excessive amount of pollutants such as heavy metals present in animal and human feed $(\mathbf{1 6}, \mathbf{1 7})$. Lead is the most common heavy toxic metal and its toxic effect has been recognized for more than 2000 years ago. Lead accumulates virtually in every tissue of the body and effects almost all the body systems especially RBCs ${ }^{(18)}$. In the line of its toxicity, Lead induces an oxidative stress promoting Reactive oxygen species production (ROS) causing rapid cellular damage ${ }^{(\mathbf{1 9}, \mathbf{2 0})}$. It well known that Lead is hemato-toxic metal (21). Its toxic effect on the haematological system induces anaemia ${ }^{(22)}$. On the other way; Lead acetate also is implicated to induce a toxic effect on haematological process as it induces reduction in $\mathrm{RBCs}, \mathrm{PCV}, \mathrm{Hb}$, $\mathrm{MCV}, \mathrm{MCH}$ and $\mathrm{MCHC}$, which revealed microcytic hypochromic anemia (23). Erythropoiesis is stimulated by the hormone erythropoietin (EPO), synthesised by the kidney ${ }^{(24)}$ and regulated by the combined effects of micro environmental and growth factors that promote the survival, proliferation and/or differentiation of erythroid progenitors, and nuclear factors that regulate the transcription of genes involved in the establishment of the erythroid phenotype (25). The factors include; Stem Cell Factor
(SCF), which plays an important role in erythropioesis as it, maintains the hematopoietic stem cells in bone marrow (26). Another Erythroid transcription factor also known as Guanine Adenine thymine adenine (GATA)-binding factor 1 or GATA-1 is a protein that in humans is encoded by the GATA-1 gene ${ }^{(27)}$. This protein plays a role in erythroid development by regulating the switch of fetal hemoglobin to adult hemoglobin ${ }^{(28)}$. Transcriptional activities of GATA factors are modulated through physical interaction with other transcription factors as Friend of GATA (FOG)-1; a protein first sought as a cell-restricted cofactor for GATA-1 in erythroid cell differentiation. The association of FOG-1 with GATA-1 is mediated through the amino-finger of GATA-1 ${ }^{(29)}$. Furthermore genetic ablation of FOG-1 in mice leads to arrested erythroid differentiation, resembling loss of GATA-1 itself ${ }^{(30)}$. In the present work, we try to examine the ameliorative effect of Costus speciosus on the toxicity of lead acetate induced deterioration of erythropioesis in experimental rats.

\section{MATERIAL AND METHODS}

Experimental design: Fifty males of Sprague-Daley rats weighting 200-250 gm were housed in groups of tens in stainless steel cages in room with temperature $23^{\circ} \mathrm{C} \pm 2{ }^{\circ} \mathrm{C}$ and relative humidity of $55 \% \pm$ $5 \%$, with a light-dark phase of 12 hours with free access to basal diets and water. All animals from all experimental groups were left to free access to water and designed basal diet all over the experimental periods. After acclimatization for 7 days, all rats were randomly assigned to five groups: Group (A) served as control they did not receive any type treatment during the experiment. 
Group (B) received I.P doses of lead acetate for 5 days consecutively at a daily dose of $50 \mathrm{mg} / \mathrm{Kg}$ Body weight. Group (C) injected with lead acetate and received aqueous extract of $C$. speciosus at a dose of $200 \mathrm{mg} / \mathrm{Kg}$ body weight for 1 week. Group (D) injected with lead acetate and received aqueous extract of $C$. speciosus at a dose of $200 \mathrm{mg} / \mathrm{Kg}$ body weight for 2 weeks. Group (E) injected with lead acetate and received aqueous extract of $C$. speciosus at a dose of $200 \mathrm{mg} / \mathrm{Kg}$ body weight for 4 weeks.

Preparation of plant extract: One-kilo gram of Costus Specious rhizomes were ground using mixer grinder and packed in to soxhlet apparatus and carried out extraction using water for Aqueous extraction, The powdered rhizome was put in to a steel container and boiled for three hours using 1.5 liters of water. The procedure was repeated for 3 times for maximum extraction. The extract was filtered using muslin cloth and again filtered using wattmann filter paper to remove any fines present. The extract was freezed using liquid nitrogen further it is subjected for liophilization at BSC, Bangalore. The yield of the extract was $t$ $1.5 \%$ w/w. aqueous extracts of Costus Specious was freely soluble in water the extract was suspended in 5\% Tween-8026 and used for oral administration. Each time fresh preparations of the extracts were prepared when required. Costus Specious extracts were administrated to rats by using stomach tube directly in to mouth (31)

Sampling protocol: Blood samples were collected from rats without anticoagulant, kept for a time, centrifuged at $3000 \mathrm{rpm}$, the resulting supernatant were collected and used for estimation of serum erythropoietin. Bone marrow from the thigh bone was taken and weighted then immediately kept in liquid nitrogen until be used for determination the mRNA expression levels of SCF, GATA-1 and FOG-1 genes.

Molecular and biochemical
determinations

Biochemical determination of serum erythropoietin using Rat EPO (Erythropoietin) ELISA Kit Catalog No: E-EL-R0007 (Elabscience Biotechnology Co.,) according to the method described by Samagawa et al. ${ }^{(32)}$.

Molecular determination of mRNA expression levels of SCF, GATA-1 and FOG-1 genes in bone marrow using semiquantitative RT-PCR.

RNA extraction: Total RNA was extracted with PAX gene ${ }^{\mathrm{TM}}$ bone marrow RNA extraction kit (30) with Cat. No. 764133 using PAX gene bone marrow RNA tubes from PreAnalytix (Qiagen $\AA$ / BD Hemogard ${ }^{\circ}$, Franklin Lakes, NJ, USA). cDNA synthesis: the first strand cDNA was synthesized using (Qiagen RT- PCR kits 20). Material No.1042845.

RT-PCR: RT-PCR was performed using SCF, GATA-1 and FOG-1 and glyceraldehyde-3-phosphate dehydrogenase (GAPDH) was used as housekeeping gene specific oligonucleotides primers pair as the following; the primer pairs for SCF were $F$ 5'-GAAGAAAACGCACCGAAGAA-3' and $\mathrm{R}$ 5'TAAGGCTCCAAAAGCAAAGC-3'.

GATA-1 primer pairs were $F$ 5'GAAGCGAATGATTGTCAGCA-3 and R 5 -TTCCTCGTCTGGATTCCATC-3'

with Accession number (NM012764). FOG-1 primer were $\mathrm{F} 5^{\prime}$ AACCGGCTACAGCAGGGTGCAGG-3, 
$\mathrm{R}$

5' -CCCTCGAGAA-

GTGTCAAGGGTCCTGGTGGTG-3), and GAPDH primer pairs were $\mathrm{F} 5$ CCCGT-AGACAAAATGGTGAAGGTC3 and $\mathrm{R}$ 5 GCCAAAGTTGTCATGGATGACC-3`.

The amplification was performed using thermal cycler (Takara MP, Japan). PCR cycling conditions was; 28-30 cycles at 95/5 minutes initial denaturation, $94^{\circ} \mathrm{C} / 2$ minutes denaturation, $55^{\circ} \mathrm{C} / 60$ secs, $53^{\circ} \mathrm{C} / 45$ secs, $60^{\circ} \mathrm{C} / 30$ secs and $60^{\circ} \mathrm{C} / 60$ secs respectively and $72^{\circ} \mathrm{C}$ elongation temperature and chilled in ice for 5minutes. Then the amplified PCR products were electrophoresed on Eithidum bromide treated $1.5 \%$ Agarose gel in $1 X$ Trisacetate EDTA running buffer ( $1 \mathrm{x}$ TAE). The electrophoresis picture was taken and analysed by Bio-doc analyser software (Biometra, Germany).

\section{Statistical analysis}

The data was processed using the statistical package for social science (SPSS Inc., Chicago, IL, version 18, USA). All results are expressed as mean \pm SD. Comparison among groups was made by Student's t-test (unpaired), One-way analysis of variance (ANOVA). Duncan's test was used for testing the inter-grouping homogeneity. Statistical significance was set $\mathrm{P} \leq 0.05$.

\section{RESULTS}

Serum erythropoietin level $(U / l)$ : There is a significant decrease in erythropoietin levels in lead acetate treated groups if compared with their control in the same duration of the experiment. While its level starts to elevate in Costus Specious extract treated groups reaching its highest level after 4 weeks of treatment table 1 . mRNA expression levels of SCF, GATA-1 and FOG-1 genes: the mRNA expression of SCF showed the highest level in lead acetate treated group. While it gradually decreased to reach its lowest level in lead acetate + Costus specious extract 4 weeks treated group. The lowest mRNA expression level of GATA-1 was shown in the lead acetate treated group. The lowest mRNA expression level of FOG-1 was shown in lead acetate treated group while it gradually increased to reach its highest expression level in lead acetate + Costus specious for 4 weeks when compared to their control group.

\section{DISCUSSION}

In the present study, we tended to test the effect of Costus speciosus on the Leadinduced toxicity on erythroid system. We used lead acetate to induce the toxicity. In the fact Lead has long been known to exert its toxic effects on the erythropoietic system that are associated with the development of anaemia ${ }^{(22)}$. Bone marrow is one of the most important targets for Lead toxicity ${ }^{(33)}$ so we choosed the bone marrow as our target for the study. In the present study, we confirmed the toxicity of Lead through its effect on Erythropoietin (EPO). The animals treated with Lead acetate as a source of Lead showed a low EPO levels (4.54 U/l) when compared with their control (6.14U/l) in the all duration of the experiment. Authors from many years ago confirmed the toxic effect of Lead on the erythropioesis (23, 34 and 35). As the problem of the Lead toxicity become a global and widespread all over the world, our duty as a researchers is to find a possible ways for treatment to save both animals/plants. An alternative way for the treatment today; is the use of medicinal plants as they are natural and save and no fear from side effects ${ }^{(1,3)}$. Over this, medicinal plants are rich in nutrients and natural ingredients used for nontraditional 
medicine ${ }^{(2)}$. Costus speciosus is an important member of these plants. It is worldwide spread and has many therapeutic applications ${ }^{(8-14)}$. We tested the effect of Costus speciosus on erythropioesis; the results showed a significant effect of Costus speciosus on EPO and some transcriptional factors in the experimental rats. EPO levels showed a significant increase in the animals treated with Costus speciosus (4.88, 5.2 and 5.74 $\mathrm{U} / \mathrm{l})$ after 1, 2, 4 weeks respectively, if compared with animals treated with Lead acetate only $(4.54 \mathrm{U} / \mathrm{l})$. We tended the increase of EPO level in Costus speciosus treated animals due to the ameliorative effect of the plant itself. The ability of the plant to increase EPO levels is a marker for improvement of erythropioesis, as it is the main stimulator of the process of erythropioesis (25). Synergistically, with EPO a transcriptional factor SCF is acting. Both EPO and SCF are needed for erythroid cell production ${ }^{(36)}$. In contrary to its effect on EPO; Costus speciosus induce high expression level of SCF in Lead treated animals. We tended this increase due to the ability of lead to increase the need of the cells to produce SCF, which is the main motivator and sensitizer of EPO production ${ }^{(37)}$. Another two factors act co-operatory to promote erythropioesis is GATA-1 and FOG-1. It is recorded that mice developed without GATA-1 are died as embryos ${ }^{(28)}$. Both GATA-1 and FOG-1 react to differentiate blood cells ${ }^{(27)}$. While their interaction mechanism/s are not clear ${ }^{(38)}$; mutations for one or both of them induce severe thrombocytopenia and dyserthropoietic anemia $^{(39-41)}$. Animals treated with Costus speciosus showed high expression levels of both GATA-1 and FOG-1 genes this illustrate the great influence of Costus speciosus on erythropioesis. In conclusion, Costus speciosus has the ability to ameliorate the toxic effect of Lead acetate on erythropioesis in rats as it elevated the EPO levels and increase the expression levels of GATA-1 and FOG-1 genes.

\section{REFERENCES}

1. Mulukuri N.V.L.S., Mondal N.B., Prasad M.R., Renuka S. and Ramakrishna K. 2011. Isolation ofditerpenoid lactones from the leaves of AndrographisPaniculata and its anticanceractivity. Int $\mathbf{J}$ PharmacogPhytochem Res; 3 (3): 39-42.

2. Sivananthan M. 2013. Antibacterial activity of 50 medicinal plants used in folk medicine. Int JBiosci; 3 (4): 104-121.

3. Sivananthan M. and Elamaran M. 2013. In vitro evaluation of antibacterial activity of chloroform extract And rographispaniculata leaves and roots, Duriozibethinus wood bark and Psidiumguajava leaves against selected bacterial strains. Int J Biomol Biomed; 3(1): 12- 19.

4. Sivananthan Manoharan, Jasmin KaurAnticancer, 2013. Antiviral, Antidiabetic, Antifungal and Phytochemical Constituents of Medicinal Plants.Am. J. PharmTech Res.; 3(4).

5. Anonymous, 2007. The wealth of Indian first supplement series (Raw material), National Institute of science communication and information Resources, CSIR, VOL2, 211, 213.

6. Kirtikar K.R. and Basu B.D. 2005. Indian medicinal plants, Vol. II, 
L.M. Allahabad: Basu Pub. ; p. 1253.

7. Bavarva J.H. and Narasimhacharya A.V. 2008. Antihyperglycemic and hypolipidemic effects of Costusspeciosus in alloxan induced diabetic rats. Phytother Res; 22(5): 620-626.

8. Eliza J., Daisy P., Ignacimuthu S. and Duraipandiyan V. 2009. Antidiabetic and antilipidemic effect of eremanthin from Costusspeciosus (Koen.)Sm., in STZ-induced diabetic rats. ChemBiol Interact; 182(1): 67-72.

9. Eliza J., Daisy P. and Ignacimuthu S. 2010. Antioxidant activity of costunolide and eremanthin isolated from Costusspeciosus (Koen ex. Retz) Sm. ChemBiol Interact; 188 (3): 467-472.

10. Vijayalakshmi M.A. and Sarada N.C. 2008. Screening of Costusspeciosus extracts for antioxidant activity. Fitoterapia; 79(3): 197198.

11. Bandara B.M., Hewage C.M., Karunaratne V. and Adikaram N.K. 1988. Methyl ester of paracoumaric acid: antifungal principle of the rhizome of Costus-speciosus. Planta Med; 54(5): 477-478.

12. Mohamad S., Zin N.M., Wahab H.A., Ibrahim P., Sulaiman S.F. and Zahariluddin A.S 2011. Antituberculosis potential of some ethnobotanically selected Malaysian plants. J Ethanopharmacol; 133(3):10211026.

13. Verma N. and Khosa R.L. 2009. Effect of Costusspeciosus and Wedeliachinensis on brain neurotransmitters and enzyme monoamine oxidase following cold immobilization stress. J Pharm Sci \& Res; 1(2): 22-25.

14. Lijuan W., Kupittayanant P., Chudapongse N., Wray S. and Kupittayanant S. 2011. The effects of wild ginger (Costusspeciosus (Koen) Smith) rhizome extract and diosgenin on rat uterine contractions. ReprodSci; 18(6): 516-524.

15. Binny K, Sunil Kumar G and Dennis Thomas 2010. Journal of Basic and Clinical Pharmacy, 1(3), 177- 181.

16. Aboul-Enein A.M., AbouElella F.N. and Abdullah E.S. 2010. Monitoring of some organ chlorines and organ phosphorus residues in imported and locally raised chicken and bovine muscles in Egypt. J Appl. Sci Res; 6(6): 600-608.

17. El-Beltagi H.S., Mohamed A.A. and Rashed M.M. 2010. Response of antioxidative enzymes to cadmium stress in leaves and roots of radish (Raphanussativus L.). Not SciBiol; 2(4): 76-82.

18. Kazmi T and Omair A. 2005. Control of Lead Poisoning in Pakistan. J Pak Med Assoc. 55(10). 409-10.

19. Salama Z.A., El-Beltagi H.S. and El-Hariri D.M. 2009. Effect of Fe deficiency on antioxidant system in leaves of three flax cultivars. Not Bot HortAgrobotCluj; 37(1): 122128.

20. Shehab G.M.G, Ahmed O.K. and El-Beltagi H.S. 2010. Nitric oxide treatment alleviates drought stress 
in rice plants (Oryza sativa). Not Bot HortAgrobotCluj; 38(1): 139148.

21. Rio, B., Froguet, R. and ParentMassin, D. 2001. In vitro effect of lead acetate on human erythropiotic progenitors. Cell biology and toxicology; 17:41-50.

22. Slowiejko KU W. W., Bestervelt D., Buroker L. L., and Piper W. N. 1990. Effects of lead on haem biosynthesis during erythroid differentiation in vitro.Toxic. In Vitro Vol. 4, No. 6, pp. 763-769.

23. Suradkar S. G., Ghodasara D.J., PritiVihol, Jatin Patel, VikasJaiswal and Prajapat K.S. 2009. Haemato-Biochemical Alterations induced by lead acetate toxicity in Wistar Rats. Veterinary World, Vol.2 (11):429-431.

24. Föller M., Huber S.M and Lang F. 2008. "Erythrocyte programmed cell death". IUBMB Life 60 (10): 661-8. doi:10.1002/iub.106. PMID 18720418.

25. Julie Vandekerckhove, Geneviève Courtois, SéverineCoulon, JeanAntoine Ribeil and Olivier Hermine. 2009. Regulation of erythropiosis. IRON_CAP. 2(4487).

26. Kent D, Copley M, Benz C, Dykstra B, Bowie M, Eaves C. 2008. "Regulation of hematopoietic stem cells by the steel factor/KIT signaling pathway". Clin. Cancer Res. 14 (7): 1926-30. doi:10.1158/1078-0432.CCR-075134.

27. Caiulo A, Nicolis S, Bianchi $P$, Zuffardi O, Bardoni B, Maraschio $\mathrm{P}$, Ottolenghi $\mathrm{S}$, Camerino $\mathrm{G}$,
Giglioni B 1991. "Mapping the gene encoding the human erythroid transcriptional factor NFE1-GF1 to Xp11.23". Hum. Genet. 86 (4): 388-90. doi:10.1007/bf00201840.

28. Wong EY, Lin J, Forget BG, Bodine DM, Gallagher PG 2004. "Sequences downstream of the erythroid promoter are required for high level expression of the human alpha-spectrin gene". J. Biol. Chem. 279 (53): 55024-33. doi:10.1074/jbc.M408886200.

29. Tsang, A. P., Visvader, J. E., Turner, C. A., Fujiwara, Y., Yu, C., Weiss, M. J., Crossley, M. and Orkin, S. H. 1997. FOG, a multitype zinc finger protein, acts as a cofactor for transcription factor GATA-1 in erythroid and megakaryocytic differentiation. Cell 90, 109-119.

30. Tsang, A. P., Fujiwara, Y., Hom, D. B. and Orkin, S. H. 1998. Failure of megakaryopoiesis and arrested erythropoiesis in mice lacking the GATA-1 transcriptional cofactor FOG. Genes Dev. 12, 1176-1188.

31. Rajesh, 2006. Screening of hypoglycemic effects of various extracts of coustus speciousus and aqoues extract of mangifera indica in normal and diabetic rats. Adissertation submitted to pharmacology department. Rajiv gendhi university of health science Bangalore. PP56-58

32. Samagawa S.; Hirada K.; Ohnota H. and Saska R. 1984. Isolation, puraplicaion and estimation of erythropoietin. J. Biological Chemistry, 259 (10), 2709-2710. 
33. Albahary C. 1972. Lead and hemopoiesis. The mechanisms and consequences of the erythropathy of occupational lead poisoning. Am. J. Med. 52, 367-378.

34. Rous, P. 2000. The effect of heavy metals boundary contaminated soil on haematological and selected biochemical parameters in blood plasma of rabbits. ActaUniversitatis-Agriculturae-et-

Silviculturae- MendelianaeBrunensis. 48 (3): 93-99.

35. Helmy, M.A., Elnaga, N.I. and Hela, S.M. 2000. Effect of administration of milk and kareish cheese on hematological values and histopathological changes in liver and brains of rat treated with lead. Alexandria J. Agril. Res. 45(2): 103-115.

36. Xingwei S., Sanford B. Krantz, Min You and Zhizhuang Zhao 1998. Synergistic Activation of MAP Kinase (ERK1/2) by Erythropoietin and Stem Cell Factor Is Essential for Expanded Erythropoiesis Blood، Vol 92, No 4 : pp 1142-1149

37. Weijia W., Daniel N. H., Wen L. C., Peter W. Z., Julie A. 2008. Synergy between erythropiotin and stem cell factor during erythropiosis can be quantitatively described without Co-signaling effects. Biotechnology and Bioengineering, Vol. 99. No5: 1261-1272.

38. Cantor A. B., and Orkin S. H. 2005. Co-regulation of GATA factors by the Friend of GATA (FOG) family of multitype zinc finger proteins. Semin. Cell Dev. Biol. 16 : 117 - 128 .

39. Nichols, K.E., Crispino J.D., oncz M. P, White J .G., Orkin S. H., Maris J. M., and Weiss M. J. 2000 . Familial dyserythropoietic anaemia and thrombocytopenia due to an inherited mutation in GATA1. Nat. Genet. $24: 266-270$.

40. Mehaffey M.G., Newton A. L., Gandhi M. J., Crossley M., and Drachman J. G. 2001. X-linked thrombocytopenia caused by a novel mutation of GATA-1. Blood. 98: $2681-2688$.

41. Freson, K. , Matthijs G., Thys C., Marien P., Hoylaerts M. F., Vermylen J. and VanGeet C. 2002. Different substitutions at residue D218 of the X-linked transcription factor GATA1 lead to altered clinical severity of macrothrombocytopenia and anemia and are associated with variable skewed $\mathrm{X}$ inactivation. Hum. Mol. Genet. 11: $147-152$. 
Table 1: Serum erythropoietin level $(U / l)$ in experimental rats

\begin{tabular}{cccc}
\hline Groups/duration & 1 week & 2 weeks & 4 weeks \\
\hline Control & $6.14 \pm 0.235^{\mathrm{ab}}$ & $6.14 \pm 0.235^{\mathrm{ab}}$ & $6.14 \pm 0.235^{\mathrm{ab}}$ \\
Lead acetate & $4.54 \pm 0.25^{\mathrm{c}}$ & $4.54 \pm 0.25^{\mathrm{c}}$ & $4.54 \pm 0.25^{\mathrm{c}}$ \\
treated & & \\
Lead acetate $+\boldsymbol{C}$. & $4.88 \pm 0.19^{\mathrm{cd}}$ & $5.2 \pm 0.2^{\mathrm{d}}$ & $5.74 \pm 0.22^{\mathrm{d}}$ \\
Specious extract & & & \\
\end{tabular}

Means \pm S.E within the table and bearing different superscripts (a, b, c and d) are significant $t$ at $\mathrm{P}<0.05$.
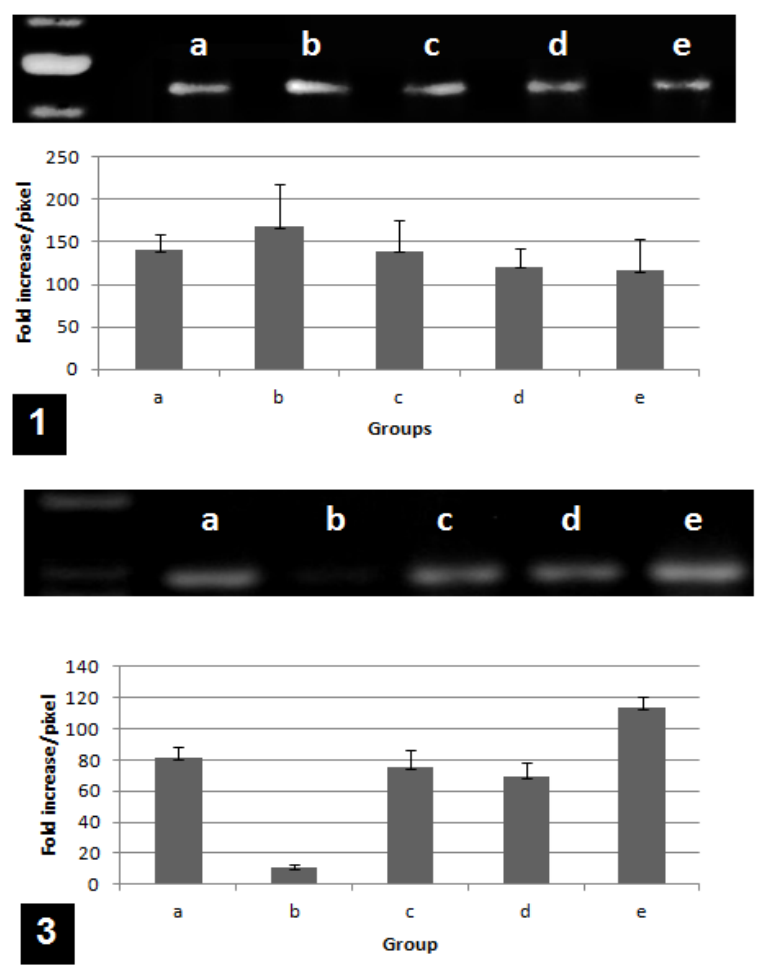

Figure 1: mRNA expression levels of (1); SCF, (2); GATA-1, (3); FOG-1, (4); GAPDH while a; control group, b; Lead acetate treated group, $\mathbf{c}$; lead acetate + C.specious treated group for 1 week, $\mathbf{d}$; lead acetate + C.specious treated group for 2 weeks, $\mathbf{e}$; lead acetate + C.specious treated group for 4 weeks. 